Elsevier required licence: (c) 2018. This manuscript version is made available under the CC-BY-NC-ND 4.0 license http://creativecommons.org/licenses/by-nc-nd/4.0/ 


\section{Impact of Membrane Orientation on the Energy Efficiency of Dual Stage Pressure Retarded Osmosis}

\section{Abstract:}

16 The performance of Dual Stage Pressure Retarded Osmosis (DSPRO) was analyzed using

17 a developed computer model. DSPRO process was evaluated on Pressure Retarded

18 Osmosis (PRO) and Forward Osmosis (FO) operating modes for different sodium chloride 19 ( $\mathrm{NaCl})$ draw and feed concentrations. Simulation results revealed that the total power 20 generation in the DSPRO process operating on the PRO mode was 2.5 to 5 times more

21 than that operating on the FO mode. For DSPRO operating on the PRO mode, the higher

22 power generation was in the case of $2 \mathrm{M} \mathrm{NaCl}$-fresh and $32 \%$ the contribution of the

23 second stage to the total power generation in the DSPRO. To the contrast, he total

24 power generated in the DSPRO operating on the FO mode was in the following order

$255 \mathrm{M}-0.6 \mathrm{M}>5 \mathrm{M}-0.7 \mathrm{M}>2 \mathrm{M}-0.01>2 \mathrm{M}-0.6 \mathrm{M}$. Interestingly, single stage process operating on

26 the FO mode performed better than DSPRO process due to the severe concentration

27 polarization effects. The results also showed that power density of the DSPRO reached a

28 maximum amount at a hydraulic pressure less than the average osmotic pressure

29 gradient, $\Delta \pi / 2$, due to the variation of optimum operating pressure of each stage. 
30 Moreover, results showed that the effective specific energy in the PRO process was

31 lower than the maximum specific energy. However, the effective specific energy of the

32 DSPRO was larger than that of the single stage PRO due to the rejuvenation of the 33 salinity gradient, emphasizing the high potential of the DSPRO process for power 34 generation.

35

36 Keyword: Salinity Gradient, Osmotic Energy, Dual Stage PRO, Renewable Energy, PRO

37 Process

38

\section{1. Introduction:}

41 Dual stage pressure retarded osmosis (DSPRO) has been recently proposed for power

42 generation using a two-stage membrane process [1-4]. Draw and feed solutions enter

43 the first DSPRO stage and diluted draw solution from the first stage goes to a second

44 membrane process to maximize energy recovery from the salinity gradient resource

45 before discharge [Figure 1]. The contribution of the second stage to the total power

46 generation in the DSPRO process depends on the salinity gradient resource and

47 operating parameters [2]. Furthermore, type and concentration of feed and draw

48 solution have a considerable impact on the performance of DSPRO process. For example,

49 experimental work has demonstrated that PRO process performs better on the FO mode

50 when feed solution contains high concentrations of fouling matters [5]. To date,

51 however, there is no study identifying the impact of membrane orientation, active layer 
52 facing draw solution (PRO mode) or active layer facing feed solution (FO mode), on the

53 performance of DSPRO process and whether a second stage will be justified when the

54 membrane orientation is switched.

55

56 Salinity gradient resource is a key parameter in the design and operation of a successful

57 DSPRO process. Seawater, RO brine, inorganic metal salts, Dead Sea brine, Rift valley

58 water, Jordan water, and Salt Lake water are some examples of the draw solutions

59 proposed [6-9]. These draw solution can be paired with a feed solution of lower osmotic

60 pressure such fresh water, wastewater effluent and seawater to create a sufficient

61 osmotic pressure gradient for water permeation across the PRO membrane. Type of

62 feed and draw solution has significant impact on the performance and operating

63 conditions of the DSPRO process. Wastewater feed solution has been found to promote

64 membrane fouling especially when the process is operated on the PRO mode; i.e. draw

65 solution faces the membrane active layer (DS-AL) [5]. Operating the PRO on the FO

66 mode, i.e. feed solution facing the active layer (FS-AL), has been reported to reduce the

67 membrane fouling propensity but also reduces the water flux [10-14]. Insufficient

68 membrane flux has been reported in the FO mode due to the inability of the membrane

69 to effectively overcome the effects of concentration polarization [8-9]. This

70 phenomenon is not fully understood in the DSPRO process, particularly in the second

71 stage in which the concentration of draw solution is different to that in the first stage. In

72 the DSPRO process, diluted draw solution from the first PRO stage is coupled with a

73 fresh feed solution in the second stage of the DSPRO process. Using fresh feed solution 
74 in the second stage rejuvenates the salinity gradient resource and expands the 75 operating conditions beyond the conventional boundaries [2]. The present study 76 evaluated the performance of the DSPRO process on the FO and the PRO operating 77 modes to identify the performance of each stage. Several salinity gradients were 78 considered in this study to investigate the impact of feed and draw solution 79 concentrations on the performance of the first and second stage of the DSPRO process.

$805 \mathrm{M}-0.6 \mathrm{M} \mathrm{NaCl}, 5 \mathrm{M}-0.7 \mathrm{M} \mathrm{NaCl}, 2 \mathrm{M}-0.01 \mathrm{M} \mathrm{NaCl}$ and $2 \mathrm{M}-0.6 \mathrm{M} \mathrm{NaCl}$ salinity gradients

81 were investigated in the DSPRO process. $5 \mathrm{M} \mathrm{NaCl}$ mimics the concentration of Dead Sea

82 solution whereas $0.6 \mathrm{M}$ and $0.7 \mathrm{M} \mathrm{NaCl}$ mimic the concentration of standard seawater $83(35 \mathrm{~g} / \mathrm{L})$ and moderate salinity seawater such as the Mediterranean Sea. On the other 84 hand, $0.01 \mathrm{M} \mathrm{NaCl}$ resembles the concentration of fresh water and $2 \mathrm{M}$ is the 85 concentration of natural salinity gradient resource such as the Salt Lake solution; 86 concentration between $50 \mathrm{~g} / \mathrm{L}$ and $270 \mathrm{~g} / \mathrm{L}[15]$.

87

88 


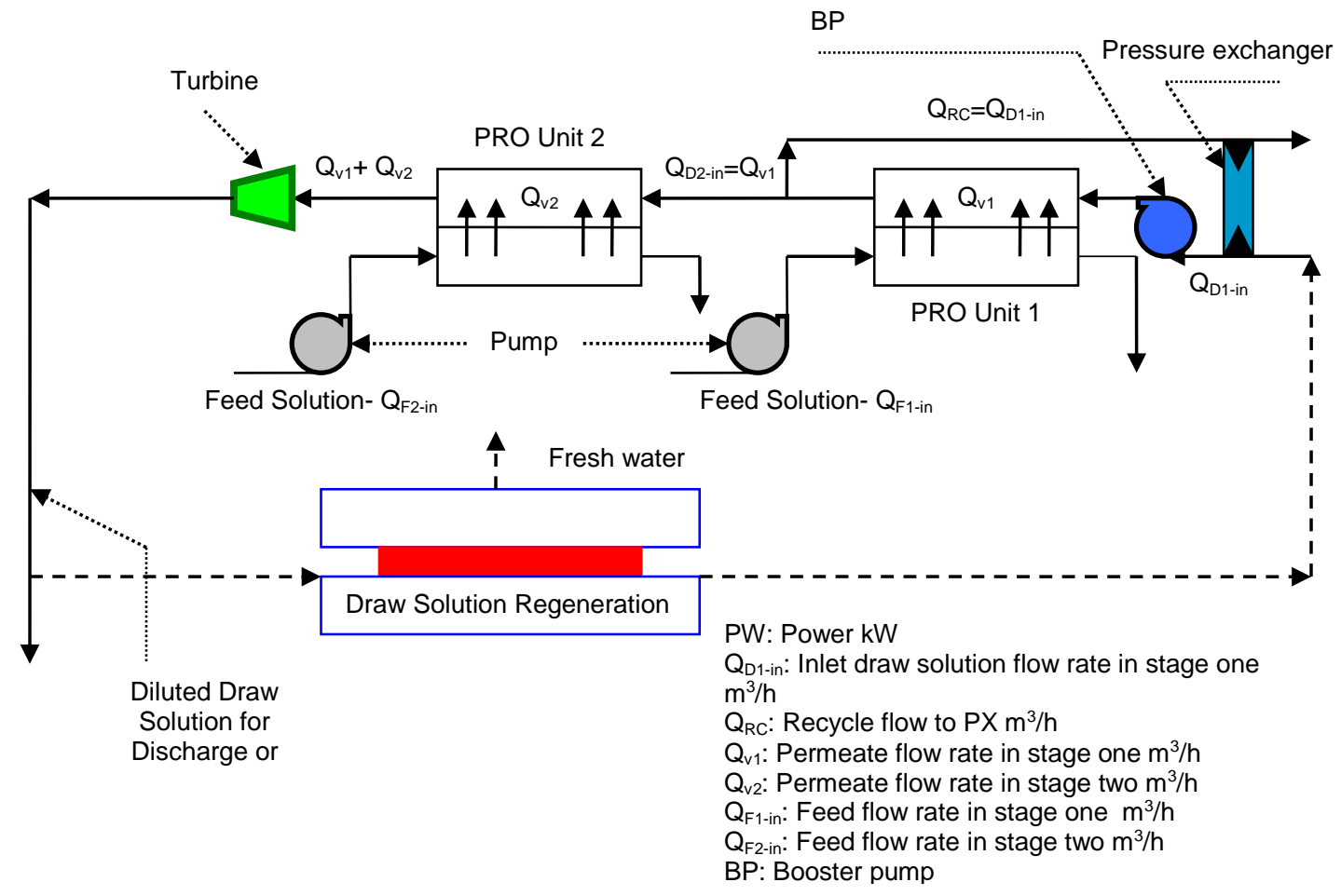

Figure 1: Dual Stage PRO process for power generation from salinity gradient resource

\section{Process Modelling}

93

94 Previous studies demonstrated that theoretical membrane flux is lower than the

95 experimental membrane flux due to the effect of concentration polarization and reverse

96 salt diffusion which is an inherent phenomenon in the membrane filtration processes

$97[16,17]$. As such, the effects of internal and external concentration polarization should

98 be accounted for in the calculations of the PRO water flux. Although many models have

99 been developed for the calculation of water flux in osmotically driven processes [18-20], 
100 the following expression has been considered relatively accurate in estimating water

101 flux in the PRO process [18, 21]:

102

103 Equation $1 \quad J_{w-P R O}=A_{w}\left(\frac{\pi_{D B} \exp \left(\frac{-J_{w}}{k_{d}}\right)-\pi_{F B} \exp \left(\frac{J_{w}}{k_{f}}+J_{w} \frac{S}{D_{f}}\right)}{1+\frac{B}{J_{w}}\left(\exp \left(\frac{J_{w}}{k_{f}}+J_{w} \frac{S}{D_{f}}\right)-\exp \left(\frac{-J_{w}}{k_{d}}\right)\right.}-\Delta P\right)$

105 where, $J_{\text {w-PRO }}$ is the membrane flux in PRO mode $\left(\mathrm{L} / \mathrm{m}^{2} \mathrm{~h}\right), \pi_{D B}$ and $\pi_{F B}$ is the osmotic

106 pressures of the bulk draw and feed solution, respectively (bar), $k_{d}$ and $k_{f}$ are the mass

107 transfer coefficient of the draw and feed solution respectively $(\mathrm{m} / \mathrm{h}), \mathrm{S}$ is the structural

108 parameter of the support layer $(\mu \mathrm{m}), D_{f}$ is the solute diffusion coefficient inside the

109 support layer $\left(\mathrm{m}^{2} / \mathrm{h}\right), B$ is the solute permeability coefficient $\left(\mathrm{kg} / \mathrm{m}^{2} \mathrm{~h}\right)$, and $K$ is the

110 solute resistivity for diffusion within the porous support layer $(\mathrm{h} / \mathrm{m})$. Equation 6

111 accounts for the effect of external mass transfer on the porous structure PRO

112 membrane process when the draw solution faces the membrane active layer (DS-AL),

113 also called as the PRO mode. It should be mentioned that the ratio of $S / D_{f}$ is equal to

114 the solute resistivity for diffusion within the support layer when facing against the feed;

$115 K_{f}(\mathrm{~s} / \mathrm{m})$. FO mode, feed solution faces the membrane active layer (FS-AL), has been

116 recommended when feed water contains high fouling matters $[12,13]$. The

117 mathematical expression to estimate membrane flux in the FO mode is $[14,18]$ :

118 
119 Equation 2

$$
J_{w-F O}=A_{w}\left(\frac{\pi_{D B} \exp \left(\frac{-J_{w}}{k_{d}}-J_{w} \frac{S}{D_{d}}\right)-\pi_{F B} \exp \left(\frac{J_{w}}{k_{f}}\right)}{1+\frac{B}{J_{w}}\left(\exp \left(\frac{J_{w}}{k_{f}}\right)-\exp \left(\frac{-J_{w}}{k_{d}}-J_{w} \frac{S}{D_{d}}\right)\right.}-\Delta P\right)
$$

120

121 where, $J_{w-F O}$ is the membrane flux when operated in the FO mode $\left(\mathrm{L} / \mathrm{m}^{2} \mathrm{~h}\right) . \mathrm{S} / D_{d}$ is the

122 solute resistivity for diffusion within the support layer when facing against the draw

123 solution; $K_{d}(\mathrm{~s} / \mathrm{m})$. We assumed that $k_{d}=k_{f}$ throughout this study. Equations 1 and 2

124 taking in the consideration the effect of external mass transfer at the porous layer in the

125 calculation of water flux in the PRO membrane [18]. We assumed $A_{w}=1.8^{*} 10^{-3}, B=4^{*} 10^{-4}$

$126 \mathrm{~m} / \mathrm{h}, k=0.18 \mathrm{~m} / \mathrm{h}, \mathrm{S}=7.2 * 10^{-4} \mathrm{~m}$, and $K=125 \mathrm{~h} / \mathrm{m}$ [18]. Additionally, Van't Hoff equation

127 ( $\pi=n C R T, \pi$ is the osmotic pressure, $n$ number of ions, $C$ molar concentration, $R$ gas

128 constant, and $T$ temperature in Kelvin) was used to estimate the osmotic pressure of

129 seawater although it may result in inaccuracies in the predicted water flux at high feed

130 and draw concentrations.

131

132 Adding a second stage PRO enhances the energy yield of the salinity gradient resource

$133[1,2]$; power generation in the first and second stage of the DSPRO process is given as

$134[2]:$

135

$136 \quad$ Equation $3 W n_{1}=\Delta P_{1}^{*} Q_{v 1}$

$137 \quad$ Equation $4 \quad P W n_{2}=\Delta P_{2} * Q_{v 2}$ 
$139 P W n_{1}$ and $P W n_{2}$ are the gross power generation in the first and second stage of the

140 DSPRO process, respectively (kW), $\Delta P_{1}$ and $\Delta P_{2}$ is the hydraulic pressure difference

141 across the membrane in the first and second stage, respectively (bar), and $Q_{v 1}$ and $Q_{v 2}$

142 are the permeate flow rates in stage one and two of the DSPRO process, respectively

$143\left(\mathrm{~m}^{3} / \mathrm{h}\right)$. Assuming that hydraulic pressure losses in the first stage of the DSPRO process

144 are negligible; i.e. $\Delta P_{1}=\Delta P_{2}$, the total power generation, $P W n$-tot, in the dual stage PRO

145 process is given as [2]:

146

147 Equation $5 \quad P W n-{ }_{t o t}=\Delta P^{*}\left(Q_{v 1}+Q_{v 2}\right)$

148

149 3. Harvesting the osmotic energy of concentrated brine

150

151 Defined as the power generated per square meter of membrane $\left(\mathrm{W} / \mathrm{m}^{2}\right)$, power density

$152(W)$ has been used as an indicator to the PRO process performance [20]. Power density

153 can be calculated from the expression shown in Equation 6 [2]:

154

155 Equation $6 \quad W=\Delta P^{*} J_{w}$

156

157 where, $\Delta P$ is the hydraulic pressure difference across the membrane (bar) and $J_{w}$ is the

158 PRO membrane flux $\left(L / \mathrm{m}^{2} \mathrm{~h}\right)$. The maximum specific power generated from a salinity

159 gradient resource can be represented by free Gibbs energy [23]. For a PRO process 
160 operating on a counter-current mode, the maximum extractable specific energy from a

161 salinity gradient resource is represented by the following equation [2]:

162

163

Equation $7 \quad E_{m}=\frac{n R T\left(C_{D}-C_{F}\right)^{2}}{4\left(C_{D}-C_{F}\right)}$

164

165 Where, $E_{m}$ is the maximum specific power generation $(\mathrm{kWh} / \mathrm{m} 3), n$ is number of ionic 166 species in solution, $R$ is the gas constant $(0.082 \mathrm{~L} \mathrm{~atm} / \mathrm{K} \mathrm{mol}), C_{D}$ and $C_{F}$ are the molar 167 concentrations of draw and feed solutions respectively $(\mathrm{M})$, and $T$ is the temperature in 168 Kelvin. Following Equation 2, $E_{m}$ increases with the increase of the draw solution 169 concentration and the decrease of the feed concentration. For simplicity, $\mathrm{NaCl}$ solution 170 was used for expressing the concentrations of feed and draw solutions in this study. The 171 maximum power generation from salinity gradient resources is explained in Figure 2.

172 Ignoring the effects of internal and external concentration polarization and reverse salt

173 diffusion, coupling Dead Sea (5M) with different seawater (SW) solutions resulted in 1.2

$174 \mathrm{kWh} / \mathrm{m}^{3}$ to $0.99 \mathrm{kWh} / \mathrm{m}^{3} E_{m}$, the lowest energy yield was for coupling Dead Sea draw 175 solution with $50 \mathrm{~g} / \mathrm{L}$ salinity SW. On the other hand, $E_{m}$ of coupling SW with FW 176 increased from $0.17 \mathrm{kWh} / \mathrm{m}^{3}$ to $0.27 \mathrm{kWh} / \mathrm{m}^{3}$ with the increase of seawater salinity from

$17732 \mathrm{~g} / \mathrm{L}$ to $50 \mathrm{~g} / \mathrm{L}$. The maximum energy harvested from Dead Sea-seawater salinity 178 gradients was 4 to 7 times higher than that from seawater- fresh water salinity gradients.

179 This was due to the large osmotic driving force across the PRO membrane in the case of 180 DS-SW salinity gradient resources. 
182 Theoretically, the mixing energy of two solutions of different concentrations would

183 result in a maximum specific energy of $E_{m}$ but this would not necessarily result in

184 equilibrium between the draw and feed solution concentrations at end of the PRO

185 process. If not recovered, this energy will be wasted with the diluted draw solution

186 discharged to sea. Incomplete osmotic energy recovery in the PRO process is partly due

187 to the phenomenon of concentration polarization in the PRO process. DSPRO process

188 with a separate feed stream to each stage has been proposed to alleviate the effect of

189 concentrated feed solution in the second stage [2, 4]. Fresh feed solution, with

190 concentration lower than that of the first stage feed brine, enhances the energy yield of

191 the second stage because of the increased net osmotic driving force. Greater osmotic

192 pressure triggers high water flux but also high internal concentration polarization as

193 shown in Figure 3. The modulus of internal concentration polarization was calculated

194 from, $e^{J_{w} K}$, and results show it was larger in the second stage of the DSPRO process with

195 fresh feed than that with feed recycle. Recycling feed solution from the first to the

196 second stage decreased the osmotic driving force and water flux across the membrane.

197 On the other hand, using a fresh feed solution in the second stage promoted higher

198 water flux which is clearly manifested in the higher internal concentration polarization

199 [Figure 3]. Therefore, fresh feed solution will be used in the second stage as illustrated

200 in the Figure 1.

201

202 


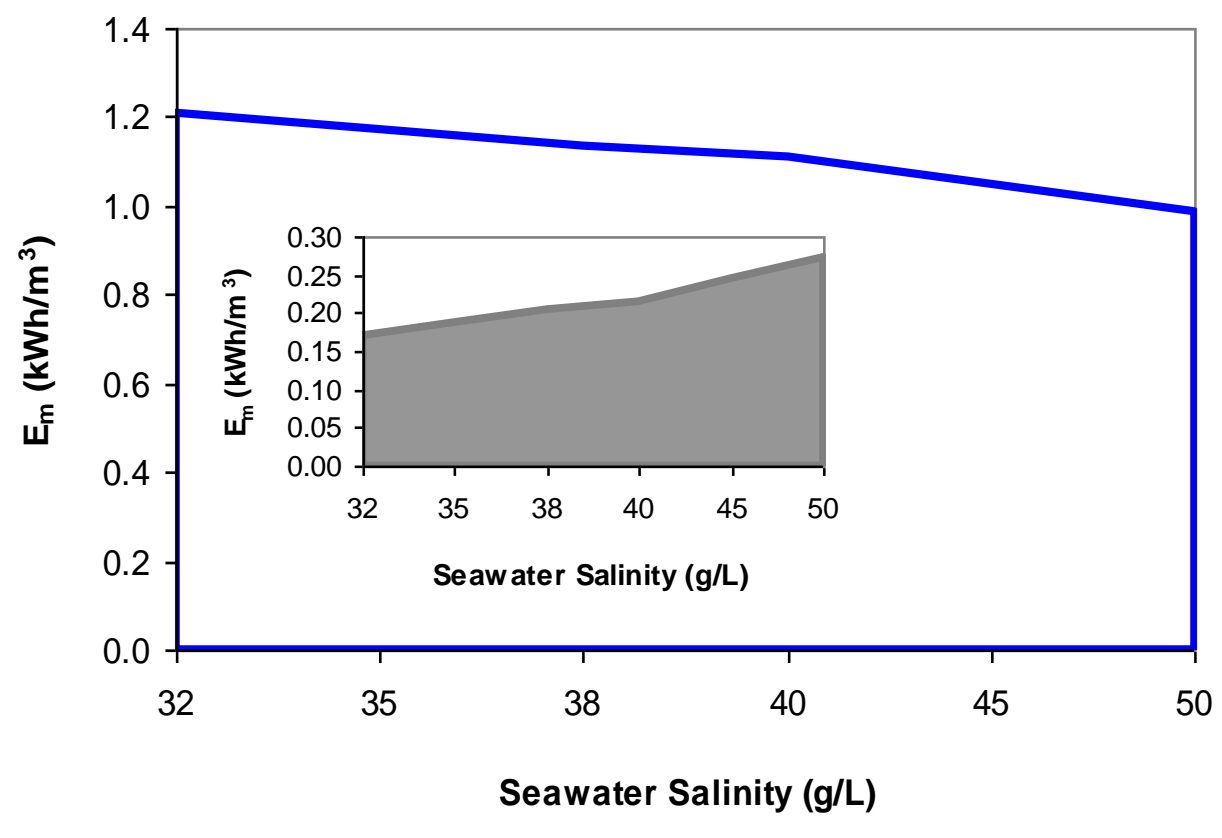

205 Figure 2: Maximum specific power generation from a number of salinity gradients made 206 of coupling Dead Sea (DS) with seawater (SW) of salinities between $32 \mathrm{~g} / \mathrm{L}$ and $50 \mathrm{~g} / \mathrm{L}$ or 207 coupling seawater (SW) with fresh water (FW).

208 


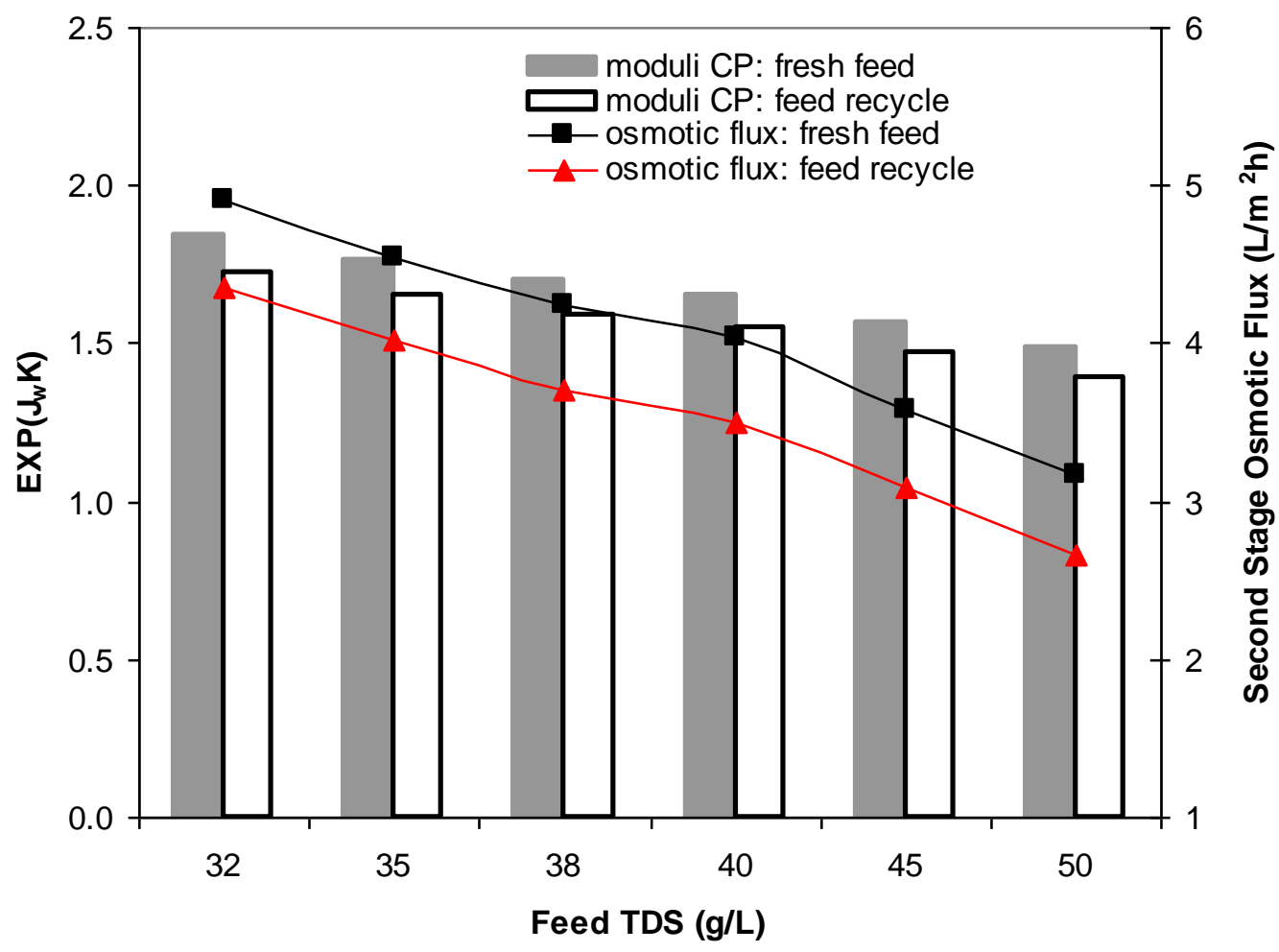

209

210 Figure 3: Modulus of internal concentration polarization and net osmotic pressure

211 across the PRO membrane for different salinity gradient resources, draw solution is $5 \mathrm{M}$

$212 \mathrm{NaCl}$, the feed and draw solution flow rates are equal, membrane flux was calculated

213 using Equation 1. Operating parameters are $A_{w}=1.8^{*} 10^{-3}, B=4 * 10^{-4} \mathrm{~m} / \mathrm{h}, k=0.18 \mathrm{~m} / \mathrm{h}$,

$214 \quad S=7.2 * 10^{-4} \mathrm{~m}$, and $K=125 \mathrm{~h} / \mathrm{m}$.

215

216 4. Performance of Dual stage PRO performance in PRO mode

217

218 Performance of the DSPRO process was evaluated in the PRO mode for 5M-0.6M, 5M-

$2190.7 \mathrm{M}, 2 \mathrm{M}-0.01 \mathrm{M}$, and $2 \mathrm{M}-0.6 \mathrm{M}$ salinity gradient resources. Results show that power

220 density of the first stage of the DSPRO process, $W_{1}$, increased with the increase of 
221 hydraulic pressure and reached a maximum amount, $W_{\max 1}$, at a hydraulic pressure

222 equals to $\Delta \pi / 2$; this observation holds for all type of the salinity gradient resources

223 [Figure 4A]. Increasing the hydraulic pressure over $\Delta \pi / 2$ resulted in a gradual decrease

224 of the $W_{1}$. For salinity gradient resources $5 \mathrm{M}-0.6 \mathrm{M}, 5 \mathrm{M}-0.7 \mathrm{M}, 2 \mathrm{M}-\mathrm{FW}$, and $2 \mathrm{M}-0.6 \mathrm{M}$,

$225 \mathrm{~W}_{\max 1}$ was $18.5 \mathrm{~W} / \mathrm{m}^{2}, 16.8 / \mathrm{m}^{2}, 27.1 \mathrm{~W} / \mathrm{m}^{2}$ and $10.1 \mathrm{~W} / \mathrm{m}^{2}$ respectively, which is higher

226 than the power density threshold of $5 \mathrm{~W} / \mathrm{m}^{2}$ recommended for an economical PRO

227 process [9]. The higher power density of $2 \mathrm{M}-\mathrm{FW}$ salinity gradient compared to other

228 salinity gradients emphasized the negative impact of internal concentration polarization

229 on the process performance. Although $5 \mathrm{M}-0.6 \mathrm{M}$ has greater osmotic driving force than

$2302 \mathrm{M}-\mathrm{FW}$ salinity gradient resource, severe internal concentration polarization associated

231 with SW feed solution in $5 \mathrm{M}-0.6 \mathrm{M}$ salinity gradient caused a significant drop in the

232 membrane flux and power density. Increasing the concentration of feed solution from

$2330.6 \mathrm{M}$ to $0.7 \mathrm{M}$ did not significantly affect the power density of the process when coupled

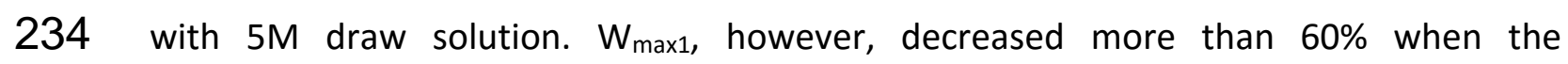

235 concentration of feed solution increased from 0.01M (for freshwater) to $0.6 \mathrm{M}$ using $2 \mathrm{M}$

236 draw solution concentration. For $0.6 \mathrm{M}$ feed solution, increasing the draw solution

237 concentration from $2 \mathrm{M}$ to $5 \mathrm{M}, 2.5$ times, did not cause a proportionate increase in

$238 \mathrm{~W}_{\max 1}$. $\mathrm{W}_{\max 1}$ increased from $10.1 \mathrm{~W} / \mathrm{m}^{2}$ for $2 \mathrm{M}-\mathrm{FW}$ to $18.5 \mathrm{~W} / \mathrm{m}^{2}$ for $5 \mathrm{M}-0.6 \mathrm{M}$ salinity

239 gradient. The disproportionate increase of $W_{\max 1}$ was due to the severe internal

240 concentration polarization and reverse salt diffusion from the draw to the feed solution.

241 The results suggest that increasing the concentration of draw solution has a limited

242 impact on the performance of PRO process in the case of high concentration feed 
243 solution. Furthermore, increasing the osmotic pressure gradient should be encountered

244 with an increase of the hydraulic pressure which could be an issue since the current

245 commercial PRO membranes do not tolerate hydraulic pressures more than 30 bar [2, 246 13].

247

248 For the second stage of the DSPRO process, $W_{2}$ increased with increasing the hydraulic 249 pressure and reached a maximum amount of $\mathrm{W}_{\max 2}$ at $\Delta P<\Delta \pi / 2$ then dropped down 250 gradually with the increase of hydraulic pressure over $\Delta \pi / 2$ due to the negligible water

251 flux [Figures $4 B$ ]. $W_{\max 2}$ was $6.8 \mathrm{~W} / \mathrm{m}^{2}, 5.5 \mathrm{~W} / \mathrm{m}^{2}, 18.3 \mathrm{~W} / \mathrm{m}^{2}$ and $3.7 \mathrm{~W} / \mathrm{m}^{2}$ for $5 \mathrm{M}-0.6 \mathrm{M}$, $2525 \mathrm{M}-0.7 \mathrm{M}, 2 \mathrm{M}-\mathrm{FW}$, and $2 \mathrm{M}-0.6 \mathrm{M}$ salinity gradient resources respectively. Results show 253 that $\mathrm{W}_{\max 2}$ was about $37 \%, 33 \%, 68 \%$, and $36 \%$ of $\mathrm{W}_{\max 1}$, respectively for $5 \mathrm{M}-0.6 \mathrm{M}, 5 \mathrm{M}$ -

$2540.7 \mathrm{M}, 2 \mathrm{M}-\mathrm{FW}$, and $2 \mathrm{M}-0.6 \mathrm{M}$ salinity gradient resources. $\mathrm{W}_{\max 2}$ was more than the 255 recommended threshold of $5 \mathrm{~W} / \mathrm{m}^{2}$ for most salinity gradient resources except $2 \mathrm{M}$ $2560.6 \mathrm{M}$ salinity gradient resource in which $\mathrm{W}_{\max 2}$ was $3.7 \mathrm{~W} / \mathrm{m}^{2}$. The results also show that 257 efficiency of the second stage of the DSPRO process was higher when fresh water was 258 the feed solution; i.e. $2 \mathrm{M}-\mathrm{FW}$, because of the negligible internal $\mathrm{CP}$ effects. Furthermore, 259 the hydraulic pressures for $\mathrm{W}_{\max 2}$ were 35 bar and 60 bar for $2 \mathrm{M}-\mathrm{FW}$ and $5 \mathrm{M}-0.6$ salinity 260 gradient respectively; the corresponding values for $W_{\max 1}$ values were 50 bar and 110 261 bar for 2M-FW and 5M-0.6 salinity gradient respectively. Results show a gap in the 262 optimum hydraulic pressures between the first and second stage of the DSPRO process 263 and this gap increases with the concentration of draw solution. Apparently, increasing 264 the concentration of draw solution induces higher water flux but promotes higher 
265 concentration polarization effects at the same. DSPRO process can partially alleviate the

266 impact of concentration polarization in the second stage in which a fresh feed solution is

267 applied. However, the maximum performance of DSPRO occurs at a hydraulic pressure

268 less than the average osmotic pressure gradient of the salinity gradient resource which

269 should be considered in the design criteria of the osmotic power plant.

270

271

272

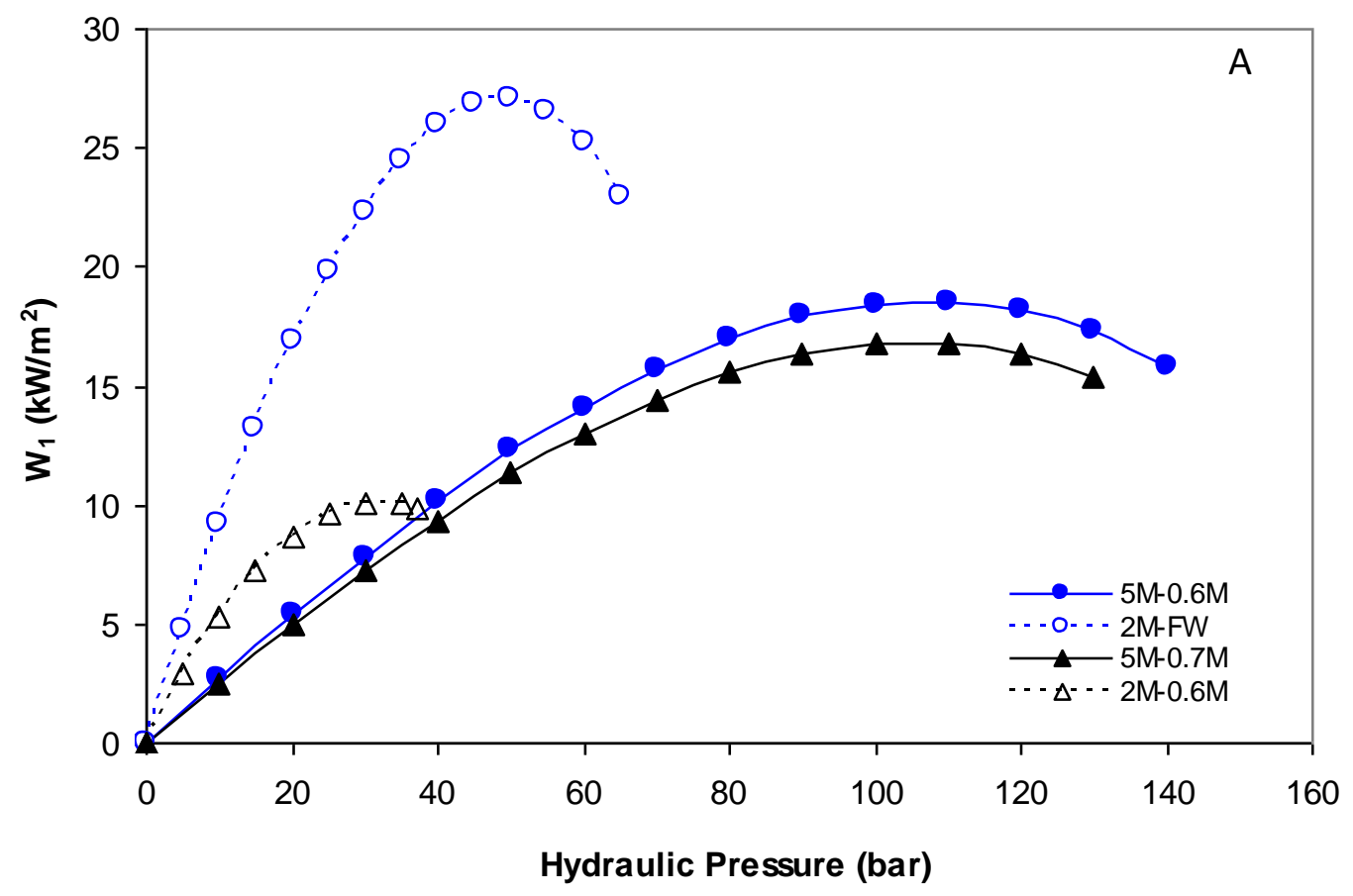

Hydraulic Pressure (bar) 


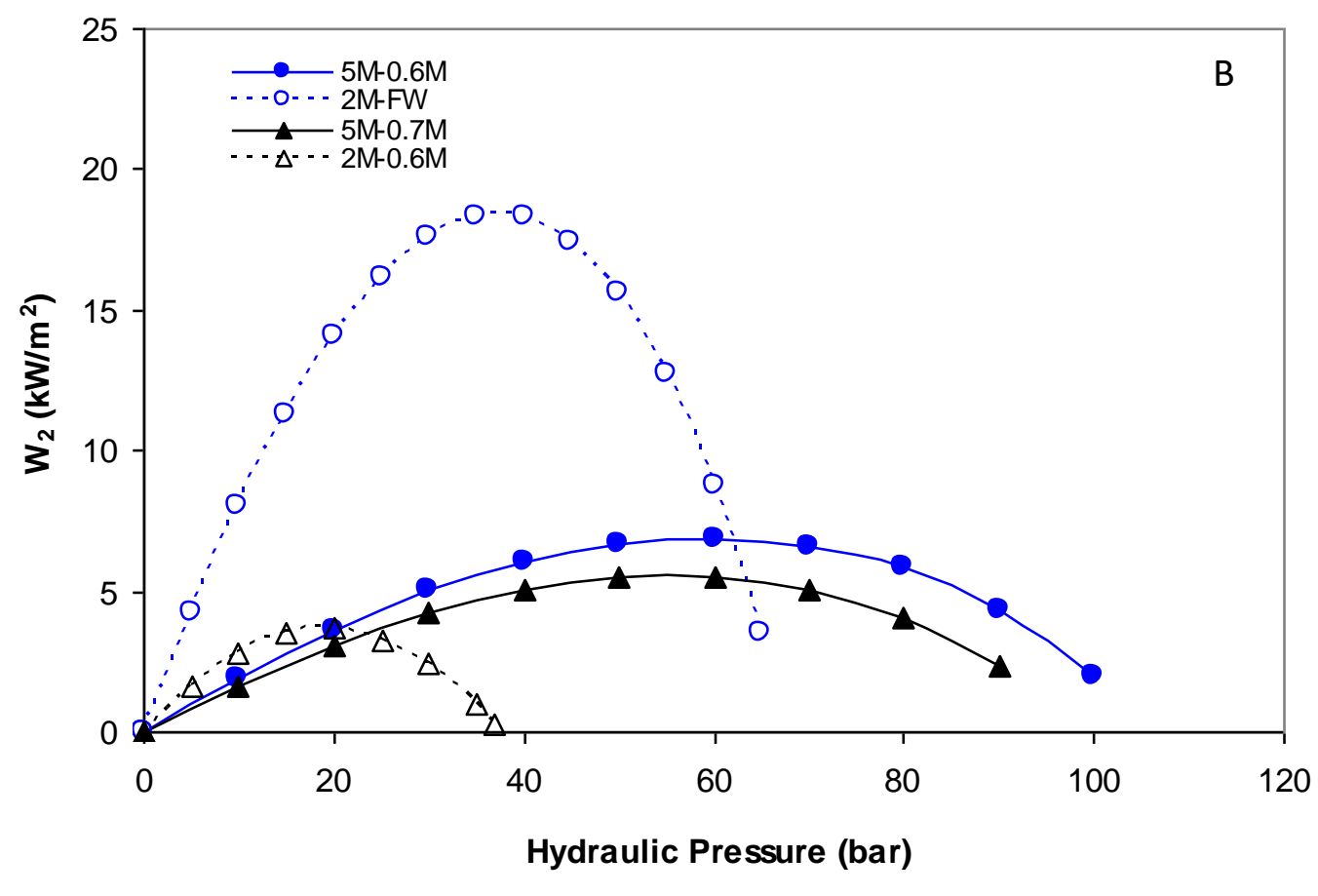

277 Figure 4: Performance of dual stage PRO process A) power density in stage one B) power

$278 \quad$ density in stage two

279

280 Power generation, PWn, of each stage of the DSPRO were calculated to find out the

281 maximum total power generation, $\mathrm{PWn}$-tot, in the DSPRO process. Figure $5 \mathrm{~A}$ and $5 \mathrm{~B}$

282 show the PWn of the first and second stage of the DSPRO process. For $5 \mathrm{M}-0.6 \mathrm{M}$ and

$2835 \mathrm{M}-0.7 \mathrm{M}$ salinity gradient resources, the range of operating hydraulic pressure in the

284 second stage was narrower than that in the first stage of the DSPRO process [Figure 5A].

285 The maximum PWn of the first stage occurred at $P=\Delta \pi / 2$; i.e. 110 bar and 100 bar for

286 the $5 \mathrm{M}-0.6 \mathrm{M}$ and $5 \mathrm{M}-0.7 \mathrm{M}$ salinity gradients respectively. On the other hand, the

287 operating pressure of the second stage ranged between 0 bar and 100 bar for $5 \mathrm{M}-0.6 \mathrm{M}$

288 salinity gradient and 0 bar and 90 bar for the $5 \mathrm{M}-0.7 \mathrm{M}$ salinity gradient. For the second 
289 stage of the DSPRO, the maximum PWn occurred at 60 bar for both $5 \mathrm{M}-0.6 \mathrm{M}$ and $5 \mathrm{M}$ -

290 0.7M salinity gradients. The maximum PWn-tot, which is the sum of first and second 291 stage PWn, occurred at 90 bar and 80 bar for the $5 \mathrm{M}-0.6 \mathrm{M}$ and $5 \mathrm{M}-0.7 \mathrm{M}$ salinity

292 gradients respectively [Figure 5C]. Interestingly, the maximum PWn-tot of the DSPRO 293 occurred at a hydraulic pressure $<\Delta \pi / 2$ for both salinity gradient resources. These

294 hydraulic pressures, however, were within the hydraulic pressures range of the first and 295 second stage of the DSPRO process.

296

297 For $2 \mathrm{M}-\mathrm{FW}$ and $2 \mathrm{M}-0.6 \mathrm{M}$ salinity gradient resources, $\mathrm{PWn}$ of the first and second stage 298 of the DSPRO process is illustrated in Figure 5B. The maximum PWn of the first and 299 second stage was $2.7 \mathrm{~kW}$ and $0.92 \mathrm{~kW}$ respectively for $2 \mathrm{M}-\mathrm{FW}$ salinity gradient resource; $300 \mathrm{PWn}$ in the second stage was about $34 \%$ of that in the first stage of the DSPRO process.

301 The maximum PWn of the first and second stage for $2 \mathrm{M}-0.6 \mathrm{M}$ salinity gradient resource 302 was $1 \mathrm{~kW}$ and $0.18 \mathrm{~kW}$ respectively. Figure $5 \mathrm{~B}$ shows that the maximum $\mathrm{PWn}$ for the 303 first stage occurred at 45 bar and 30 bar for $2 \mathrm{M}-\mathrm{FW}$ and $2 \mathrm{M}-0.6 \mathrm{M}$ salinity gradient 304 respectively. The corresponding values for the second stage were at 35 bar and 20 bar 305 for 2M-FW and 2M-0.6M salinity gradient respectively. Additionally, the maximum PWn306 tot for $2 \mathrm{M}-\mathrm{FW}$ and $2 \mathrm{M}-0.6 \mathrm{M}$ was at 45 bar and 25 bar respectively. In effect, these 307 hydraulic pressures were within the range of hydraulic pressure in the second stage of $3082 \mathrm{M}-\mathrm{FW}$ and $2 \mathrm{M}-0.6 \mathrm{M}$. Furthermore, the maximum $\mathrm{PWn}-$ tot of $2 \mathrm{M}-\mathrm{FW}$ was three times 309 higher than that for $2 \mathrm{M}-0.6 \mathrm{M}$ salinity gradient because of the higher net driving force.

310 
311 Results show that the maximum PWn-tot was $3.7 \mathrm{~kW}$ and achieved by $2 \mathrm{M}-\mathrm{FW}$ salinity

312 gradient then followed by $2 \mathrm{~kW}$ for $5 \mathrm{M}-0.6 \mathrm{M}, 1.8 \mathrm{~kW}$ for $5 \mathrm{M}-0.7 \mathrm{M}$, and finally $1.1 \mathrm{~kW}$

313 for $2 \mathrm{M}-0.6 \mathrm{M}$. Low internal concentration polarization on the feed side of the $2 \mathrm{M}-\mathrm{FW}$

314 salinity gradient was the trigger for high $\mathrm{PWn}$-tot compared to other salinity gradients

315 which indicates to the significance of feed concentration on the performance of DSPRO.

316 Increasing the concentration of draw solution positively affected the performance of

317 DSPRO but intensifies the effect of concentration polarization and reverse salt diffusion.

318 Introducing a second stage PRO process maximized the energy yield of the process;

319 however, the lower the salinity of feed solution the higher the performance of DSPRO.

320 Fresh water is preferred over a saline feed solution if available to be coupled with a

321 suitable draw solution for the DSPRO process.

322

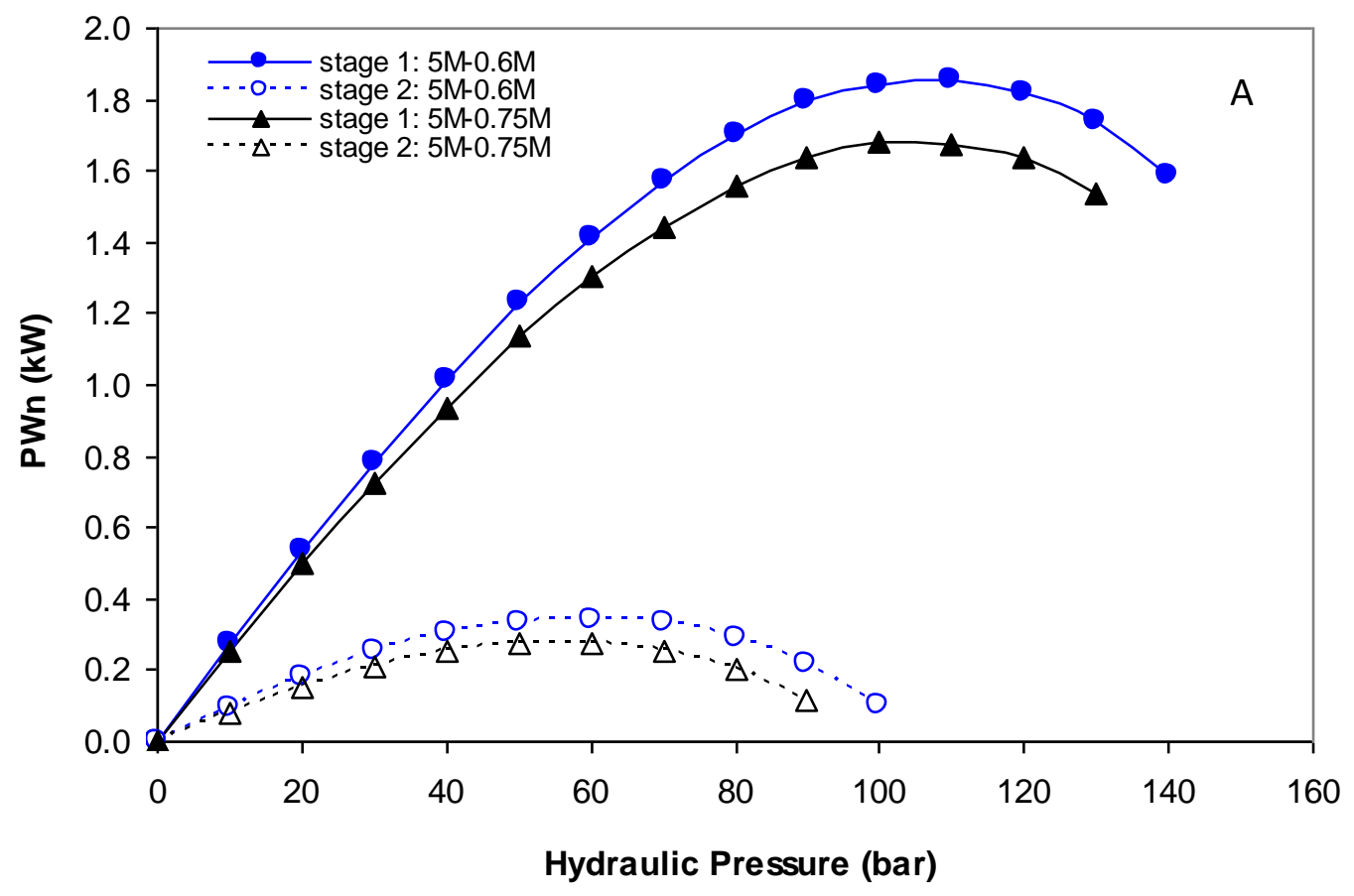

323 
325

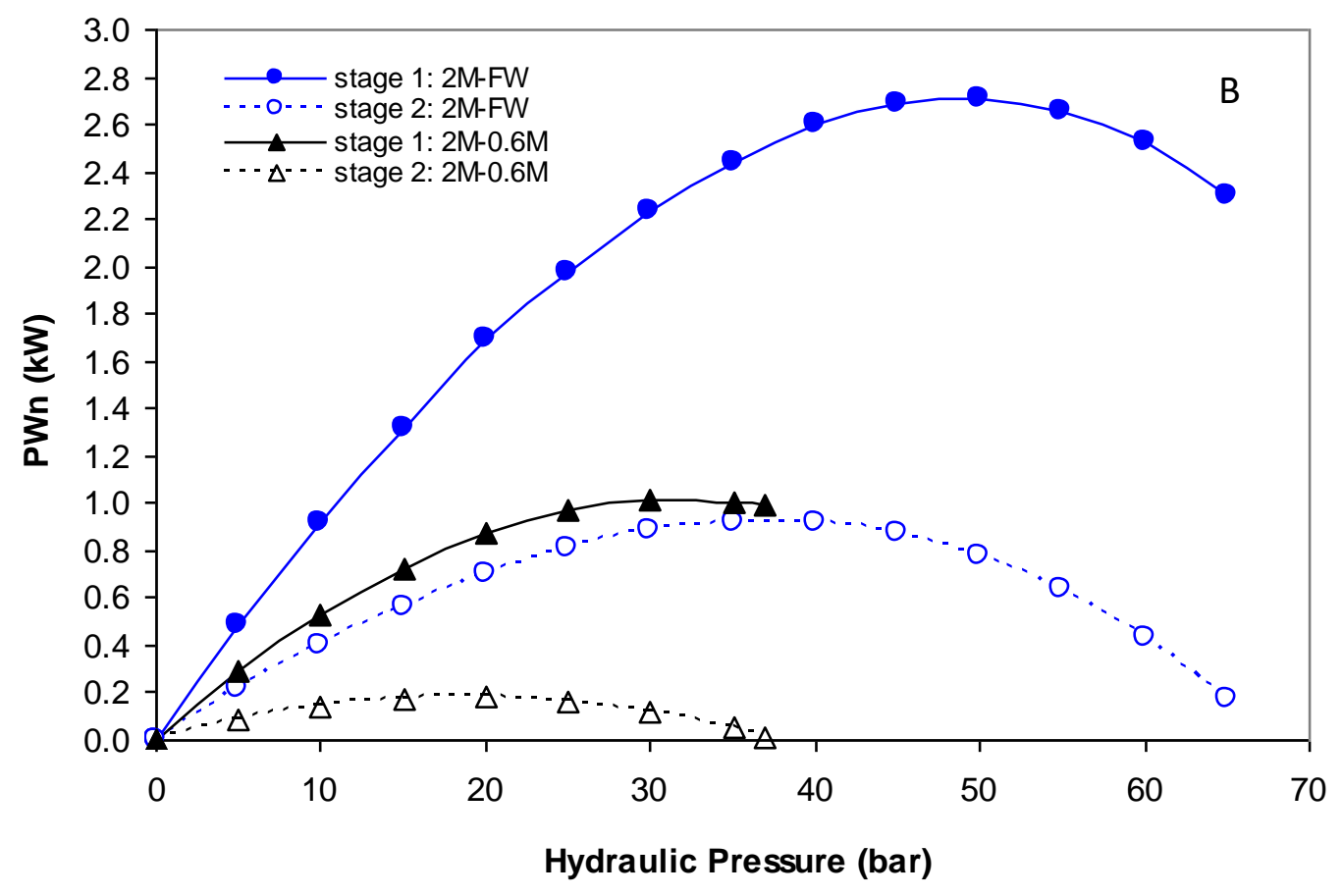

326

327

328 


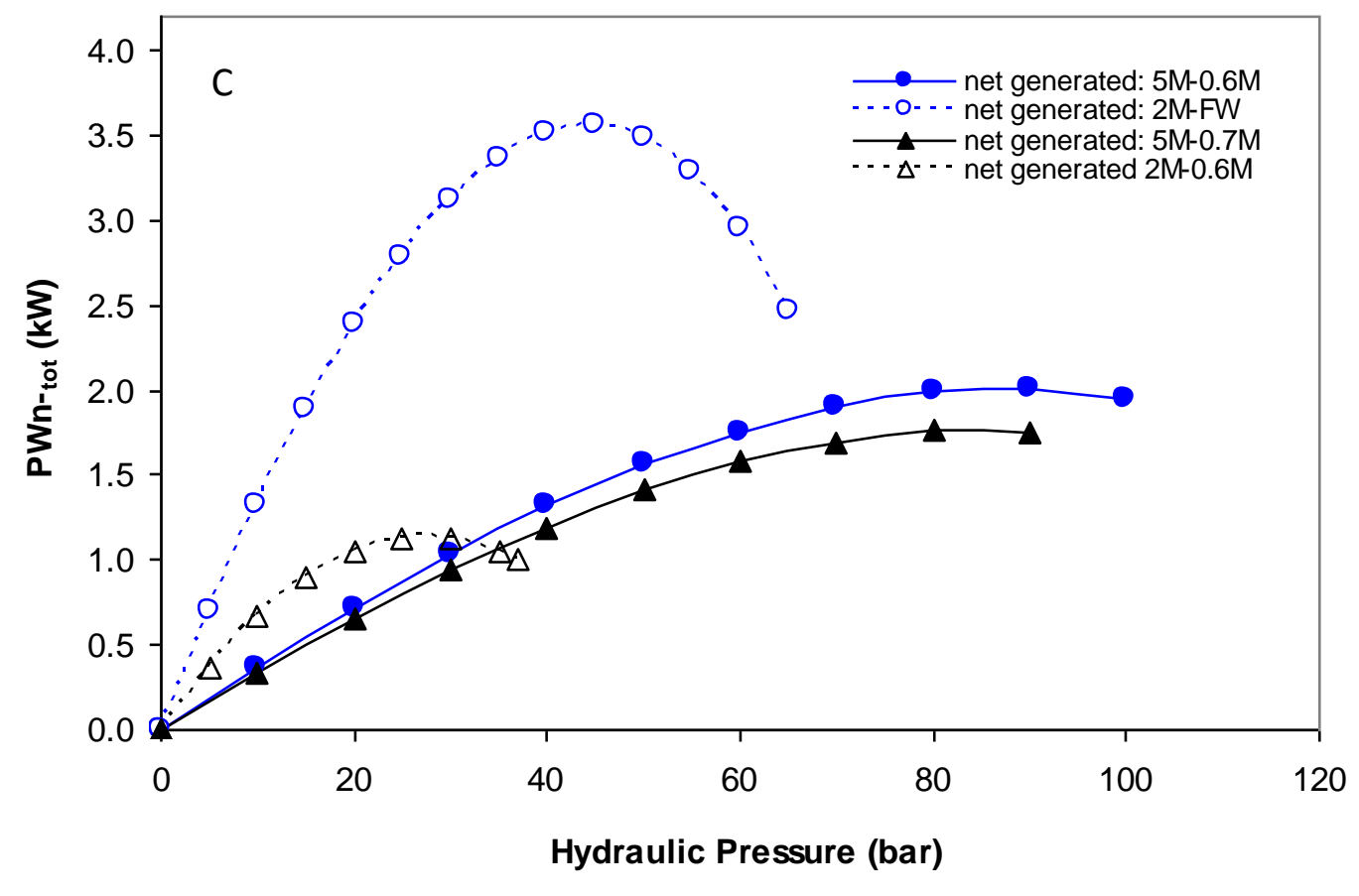

330 Figure 5: Power consumption in the dual stage PRO process A) net power generation for

$3315 \mathrm{M}-0.6 \mathrm{M}$ and $5 \mathrm{M}-0.7 \mathrm{M}$ salinity gradient resource $\mathrm{B}$ ) net power generation for $2 \mathrm{M}-\mathrm{FW}$

332 and $2 \mathrm{M}-0.6 \mathrm{M}$ salinity gradient resource $\mathrm{C}$ ) total net power generation in the PRO

$333 \quad$ process, $\mathrm{PWn}$-tot

334

335 5. Dual stage PRO performance in FO mode:

336

337 The performance of DSPRO process operating on the FO mode was evaluated and

338 compared with that on the PRO mode [Figure 6]. For $5 \mathrm{M}-0.6 \mathrm{M}$ and $5 \mathrm{M}-0.7 \mathrm{M}$ salinity

339 gradient resources, power density of the first stage increased with increasing the

340 hydraulic pressure and reached a maximum amount, $W_{\max 1,}$ of $8.1 \mathrm{~W} / \mathrm{m}^{2}$ and $7.2 \mathrm{~W} / \mathrm{m}^{2}$

341 at 80 bar and 70 bar hydraulic pressures respectively [Figure 6A]. These hydraulic 
342 pressures were less than $\Delta \pi / 2$ and was due to large difference between the theoretical

343 and effective osmotic driving force as will be illustrated in the following section. $\mathrm{W}_{\max }$

344 for $2 \mathrm{M}-\mathrm{FW}$ and $2 \mathrm{M}-0.6 \mathrm{M}$ salinity gradient was $5.6 \mathrm{~W} / \mathrm{m}^{2}$ and $2.5 \mathrm{~W} / \mathrm{m}^{2}$ at 30 bar and 25

345 bar respectively which are slightly deviated from $\Delta \pi / 2$. The highest power density in

346 the FO mode belongs to $5 \mathrm{M}-0.6 \mathrm{M}$ salinity gradient followed by $5 \mathrm{M}-0.7 \mathrm{M}, 2 \mathrm{M}-\mathrm{FW}$ and

$3472 \mathrm{M}-0.6 \mathrm{M}$ salinity gradients respectively. Changing the operating mode from PRO to FO

348 mode caused about $80 \%$ reduction in the power density of $2 \mathrm{M}$-FW salinity gradient. This

349 refers to the fact that internal concentration polarization has more serious impact on

350 the process performance than the external concentration polarization hence; higher

351 osmotic driving force would be required in the former operating mode. Table 1 shows

352 the maximum power density of the first and second stage of the DSPRO and hydraulic

353 pressures. $W_{\max 1}$, in general, was lower in the FO mode than in the PRO mode for all

354 salinity gradient resources.

355

356 For the second stage of the DSPRO process, the maximum power density, $\mathrm{W}_{\max 2}$, for all

357 salinity gradients occurred at a hydraulic pressure less than that of the first stage [Figure

$3586 \mathrm{~A}] . \mathrm{W}_{\max 2}$ for $5 \mathrm{M}-0.6 \mathrm{M}$ and $5 \mathrm{M}-0.7 \mathrm{M}$ salinity gradients was, respectively, $63 \%$ and $75 \%$

359 lower than that at the PRO mode. For $2 \mathrm{M}-\mathrm{FW}$ and $2 \mathrm{M}-0.6 \mathrm{M}$ salinity gradients, more

360 than $80 \%$ of power density was lost by changing the operating mode from the PRO to FO

361 mode. Additionally, $W_{\max 2}$ for all salinity gradient resources was lower than the

362 threshold of $5 \mathrm{~W} / \mathrm{m}^{2}$ which is has been suggested for an economic PRO process [Table 1].

363 Apparently, PRO process suffers when it is operated on the FO mode although it was 
364 recommended in the case of impaired quality feed solutions to reduce membrane

365 fouling [5]. But this would be achieved on the expense of power density and should be

366 accounted for in the early stage of the process design.

367

368 Power generation, PWn, of the first and second stage of the DSPRO process was

369 calculated to evaluate the process efficiency (Figure 6B). There was a mismatch of the

370 optimum hydraulic pressure of the first and second stage of the DSPRO process. For 5M-

$3710.6 \mathrm{M}$ salinity gradient, the maximum power generation was $0.81 \mathrm{~kW}$ and $0.13 \mathrm{~kW}$ for

372 the first and second stage of the DSPRO process at 80 bar and 30 bar respectively, and

373 the maximum $\mathrm{PWn}$-tot was $0.82 \mathrm{~kW}$ at 50 bar. The hydraulic pressure gap between the

374 first and second stage of the DSPRO process was 50 bar for the $5 \mathrm{M}-0.7 \mathrm{M}$ salinity

375 gradient. The maximum PWn was $0.72 \mathrm{~kW}$ and $0.07 \mathrm{~kW}$ for the first and second stage at

37670 bar and 20 bar respectively, but the maximum PWn-tot was $0.64 \mathrm{~kW}$ at 45 bar. As a

377 matter of fact, the maximum PWn of the first stage was $0.72 \mathrm{~kW}$ at $70 \mathrm{bar}$; this hydraulic

378 pressure was out of the hydraulic pressure range of the second stage which was

379 between 0 bar and 45 bar. In such cases it is, probably, better to apply a single stage

380 PRO process. For the $2 \mathrm{~m}$-FW salinity gradient, the maximum PWn was $0.56 \mathrm{~kW}$ and 0.2

$381 \mathrm{~kW}$ at 30 bar for the first and second stage of the DSPRO respectively [Figure 6B]. The

382 maximum $\mathrm{PWn}$-tot was $0.74 \mathrm{~kW}$ at 30 bar; this was $20 \%$ of the maximum $\mathrm{PWn}$-tot on the

383 PRO mode and attributed to the severe concentration polarization effects. For $2 \mathrm{M}-0.6 \mathrm{M}$

384 salinity gradient, the maximum PWn of the first stage was $0.22 \mathrm{~kW}$ at 25 bar and was

$3850.03 \mathrm{~kW}$ at 10 bar for the second stage of the DSPRO process. However, the maximum 
$386 \mathrm{PWn}$-tot was $0.23 \mathrm{~kW}$ at 20 bar; this hydraulic pressure lies at the upper hydraulic

387 pressure range of the second stage which rendered its contribution to the maximum

388 PWn-tot insignificant [Figure 6C]. Therefore, adding a second stage PRO process can not

389 be justified in such case.

390

391 In general, the performance of DSPRO was better on the PRO mode. The contribution of

392 the second stage of the DPSRO was insignificant for most salinity gradients when the 393 process was operating on the FO mode. This was due to the severe impact of

394 concentration polarization on the water flux. Despite the advantages of FO operating 395 mode, it has been recommended to reduce the membrane fouling when wastewater 396 effluent is the feed solution [5]. In such cases, the feed solution would be facing the 397 membrane active layer to avoid serious fouling problems caused by the organic 398 constituents in the feed solution [25]. For example, Megaton pilot plant which uses RO

399 brine and wastewater effluent as the salinity gradient resource is operating on the FO 400 mode [13]. The pilot plant satisfactory performance could be attributed to the advanced 401 specifications of the PRO membrane used in the process.

402

403 


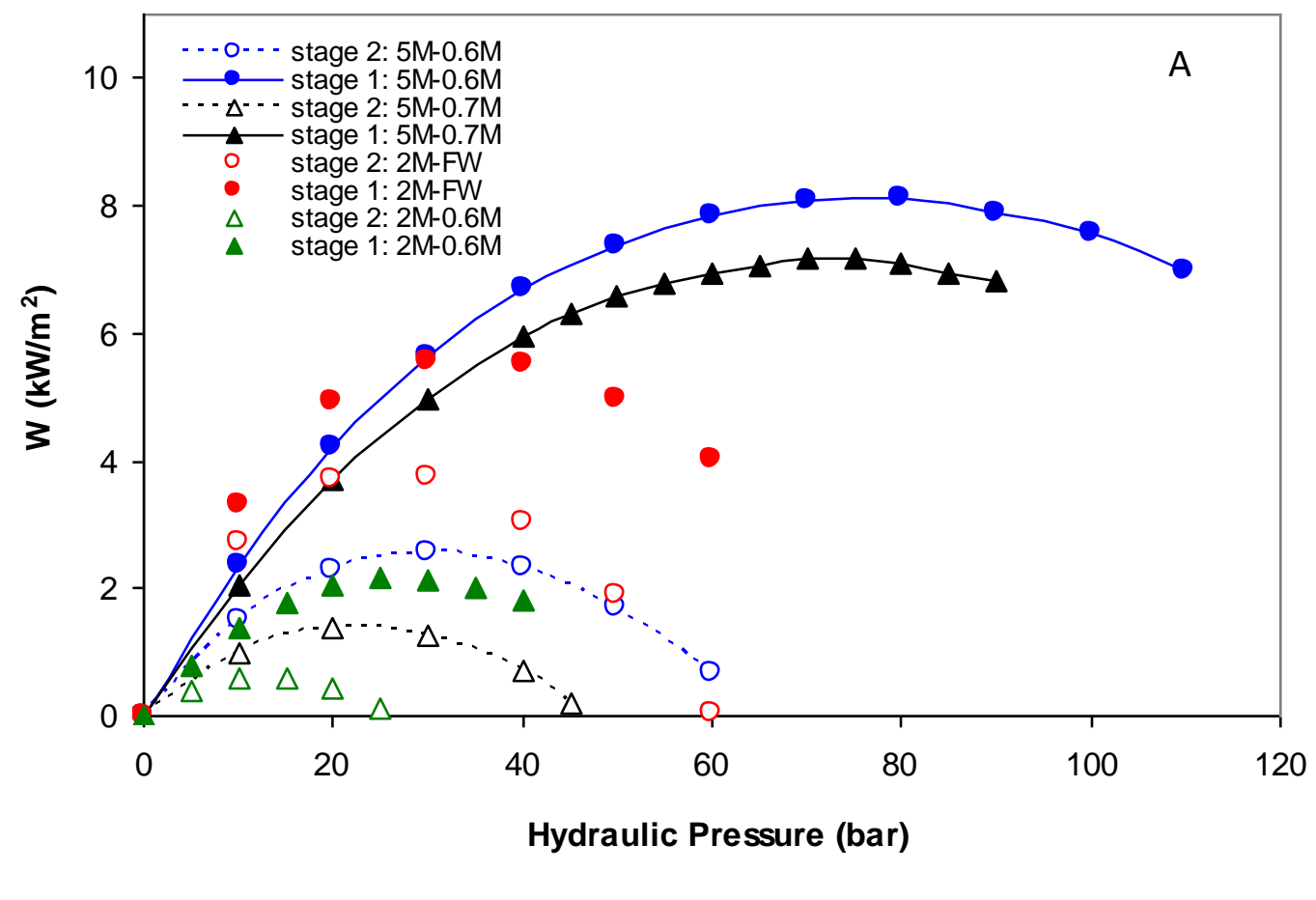

405

406

407 


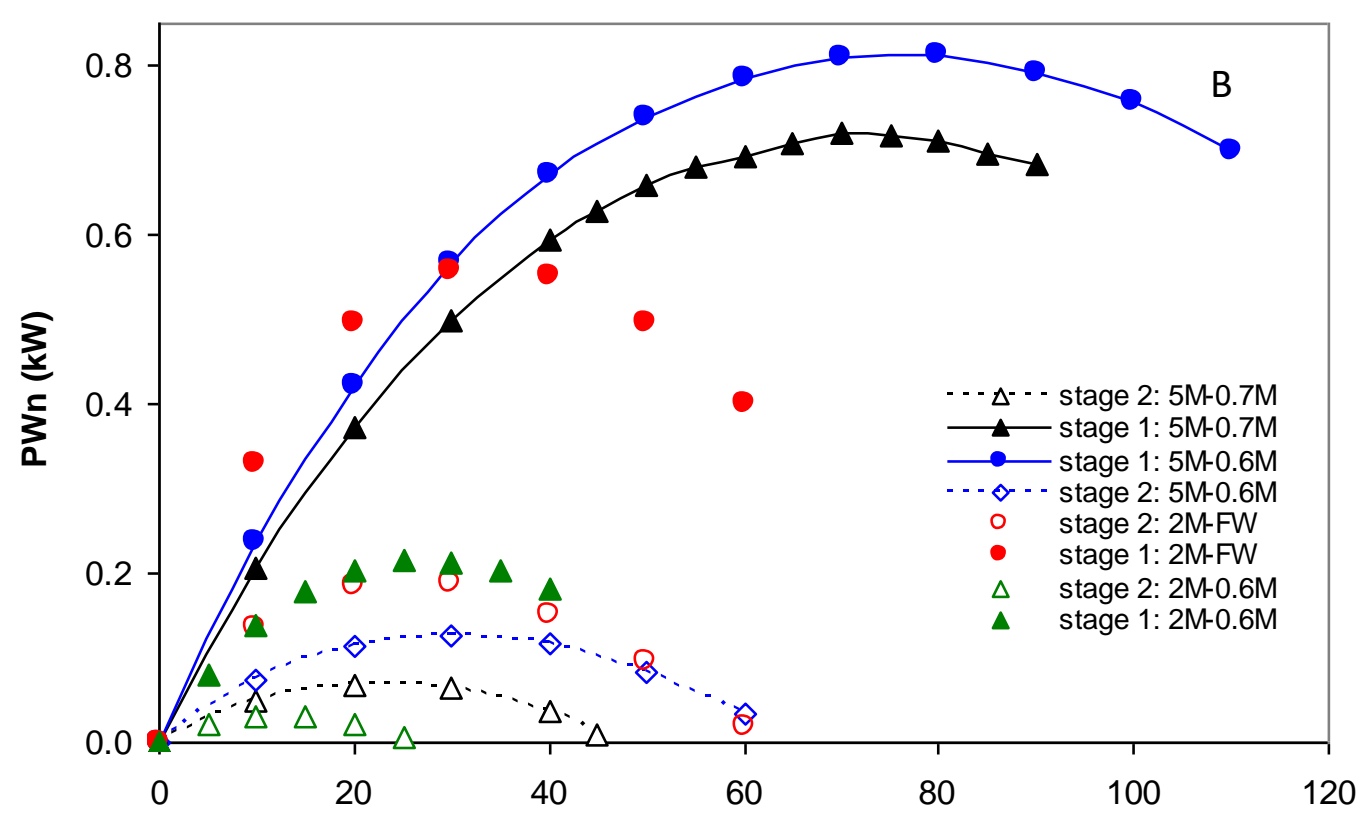

408

Hydraulic Pressure (bar)

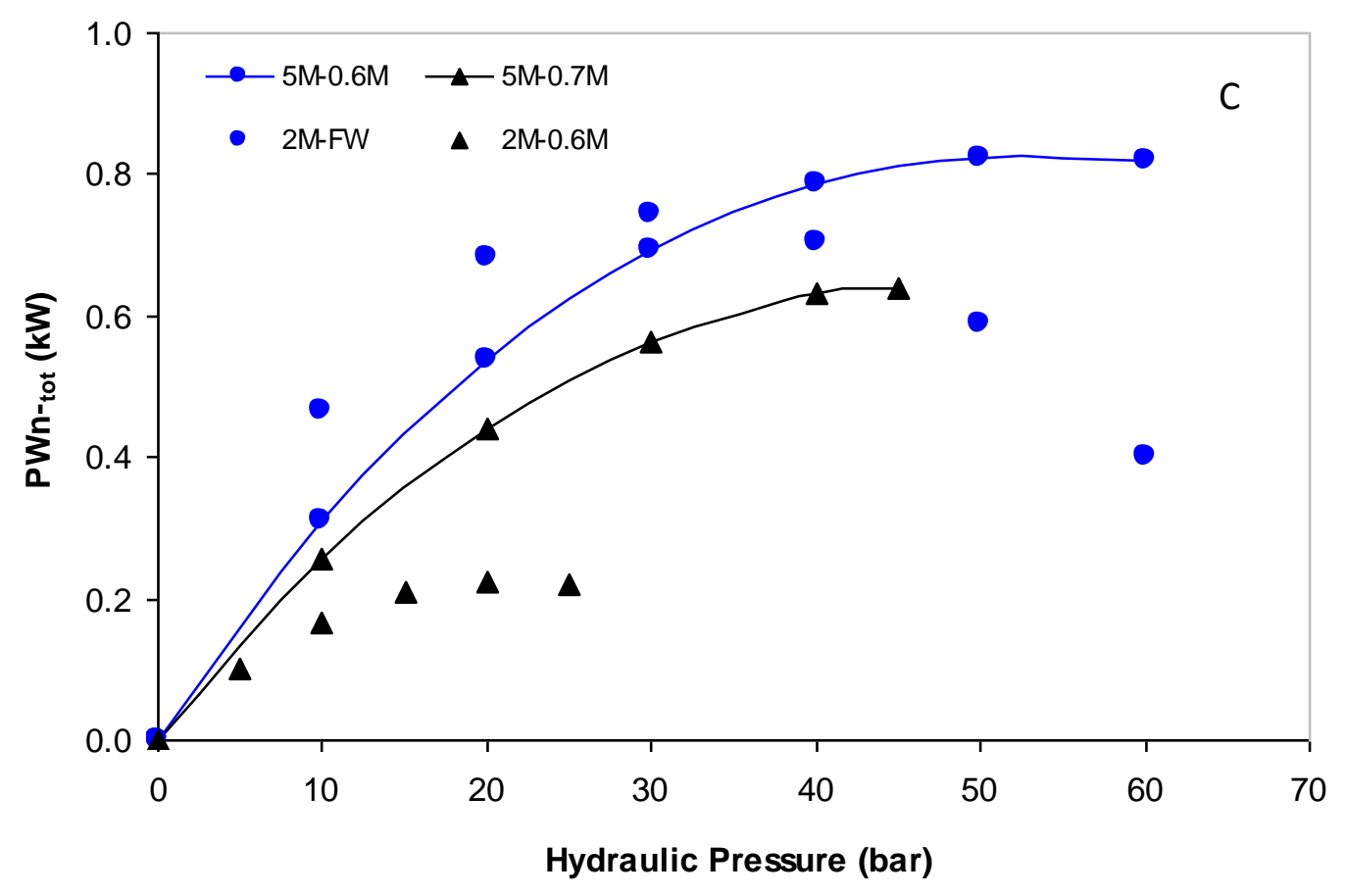

410 Figure 6: Performance of dual stage PRO process (FO Mode) A) power density B) PWn C) 
413 Table 1: maximum power density of the first and second stage of the DSPRO process,

414 total power generation and the hydraulic pressure for $5 \mathrm{M}-0.6,5 \mathrm{M}-0.7 \mathrm{M}, 2 \mathrm{M}-\mathrm{FW}, 2 \mathrm{M}-$

$4150.6 \mathrm{M}$ salinity gradients. $\mathrm{P}_{1}$ and $\mathrm{P}_{2}$ are the hydraulic pressure of the first and second stage

416 of the DSPRO process, $\mathrm{P}$ is the hydraulic pressure at which power density reaches a

417 maximum amount for the DSPRO system

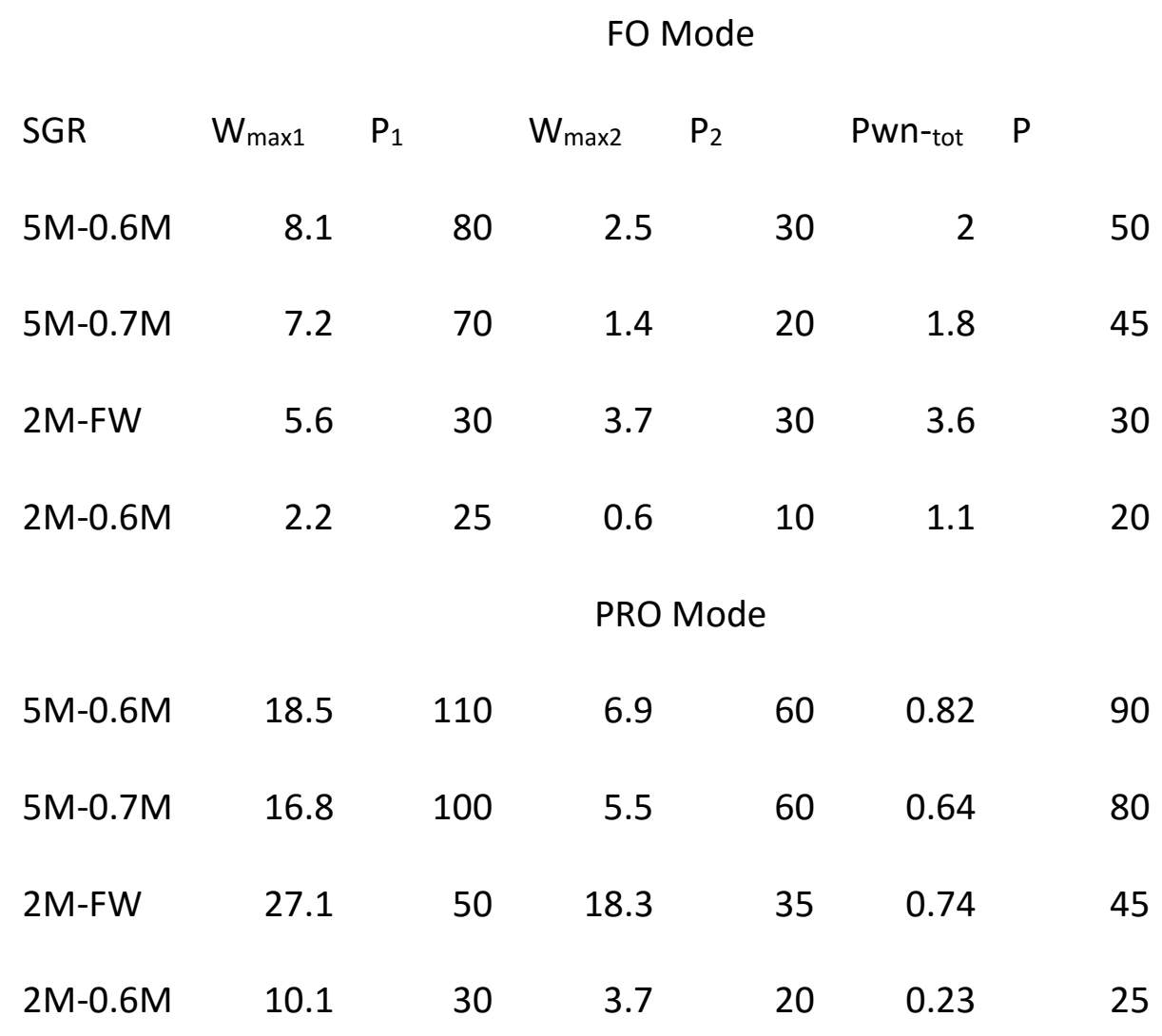

418

419 6. Effective salinity gradient resource:

420

421 Maximum specific energy, $E_{m}$, is the maximum energy can be extracted from a salinity

422 gradient resource in the PRO process at designated hydraulic pressure. In non-ideal PRO 
423 system, $E_{m}$ is affected by the intrinsic properties of the PRO membrane during the

424 filtration process. Therefore, there is a gap between the theoretical $E_{m}$ and effective

425 specific energy $E_{\text {eff }}$ due to the difference between the theoretical and the effective

426 concentrations of feed and draw solutions at the membrane surface. In the ideal system,

427 the theoretical maximum specific energy, $E_{m}$, does not include the effects of

428 concentration polarization (CP) and reverse salt diffusion (RSD) while the $E_{\text {eff }}$ should

429 account for these effects in the calculation of osmotic energy. During the filtration

430 process, the effective concentration of draw and feed solutions at the membrane

431 surface, $C_{D M}$ and $C_{F M}$ respectively, are affected by the internal, external concentration

432 polarization and reverse salt diffusion phenomena which result in the dilution and

433 concentration of the draw and feed solution respectively. The intrinsic properties of PRO

434 membrane and type of salinity gradient resource determine the amount of these effects

435 on the $E_{\text {eff. }}$

436

437 The total effective specific energy, $E_{\text {efft }}$, was calculated as the sum of $E_{\text {eff }}$ in the first and

438 second stage of the DSPRO process, $E_{\text {efft }}=E_{\text {eff } 1}+E_{\text {eff2 }}$, and results were compared with the

$439 E_{m}$ to highlight the adverse impact of $C P$ and RSD. $C_{D M}$ and $C_{F M}$ were calculated on the

440 FO and PRO modes for each stage of the DSPRO process for $5 \mathrm{M}-0.6 \mathrm{M}$ and $5 \mathrm{M}-0.68 \mathrm{M}$

441 salinity gradient resources knowing that the outlet concentration of draw solution from

442 the first stage were the inlet concentrations of the second stage. $E_{m}$ was calculated at

$443 P=\Delta \pi / 2$ and compared with the $E_{\text {eff }}$ obtained at 50 bar and 45 bar for $5 \mathrm{M}-0.6 \mathrm{M}$ and

$4445 \mathrm{M}-0.7 \mathrm{M}$ salinity gradient operating on the FO mode, respectively. The corresponding 
445 values for $5 \mathrm{M}-0.6 \mathrm{M}$ and $5 \mathrm{M}-0.7 \mathrm{M}$ salinity gradients operating on the PRO mode were 90

446 bar and 80 bar respectively. As mentioned before, these hydraulic pressures are the

447 optimum operating pressures for the DSPRO process; i.e. $E_{\text {eff }}$ reaches a maximum

448 amount. Furthermore, it is worth reminding here that $E_{m}$ for $5 \mathrm{M}-0.6 \mathrm{M}$ and $5 \mathrm{M}-0.7 \mathrm{M}$

449 salinity gradients at $P=\Delta \pi / 2$ was $1.17 \mathrm{kWh} / \mathrm{m}^{3}$ and $1.11 \mathrm{kWh} / \mathrm{m}^{3}$ respectively. In the

450 case of DSPRO and $5 \mathrm{M}-0.6 \mathrm{M}$ salinity gradient, the calculated $E_{\text {eff } 1}$ was $0.54 \mathrm{kWh} / \mathrm{m}^{3}$ and

$4510.37 \mathrm{kWh} / \mathrm{m}^{3}$ in the PRO and FO modes respectively; the corresponding values of $E_{\text {eff2 }}$

452 were $0.65 \mathrm{kWh} / \mathrm{m}^{3}$ and $0.51 \mathrm{kWh} / \mathrm{m}^{3}$ in the PRO and FO modes respectively [Figure 7A].

453 According to these results, $E_{\text {eff } 1}$ was only $46 \%$ and $32 \%$ of the $E_{m}$ for DSPRO process

454 operating on the PRO and FO mode respectively; the corresponding values for $E_{\text {eff } 2}$ were

$45555 \%$ and $44 \%$ of the $E_{m}$ for DSPRO process operating on the PRO and FO modes

456 respectively. CP and RSD are responsible for the underperformance of the DSPRO

457 process, i.e. $E_{\text {eff }}<E_{m}$, and these effects were more severe in the first stage than in the

458 second stage of the DSPRO process because of the larger permeation flow which 459 resulted in a higher dilution and concentration of the draw and feed solution 460 respectively. On the other hand, $E_{\text {efft }}$ was $1.19 \mathrm{kWh} / \mathrm{m}^{3}$ and $0.88 \mathrm{kWh} / \mathrm{m}^{3}$ on the PRO

461 and FO mode, respectively. Apparently, $E_{\text {efft }}$ of the PRO mode approached the $E_{m}$ of 5M-

$4620.6 \mathrm{M}$ salinity gradient resource. Mainly, this was due to i) replacement of feed solution

463 brine of the second stage with a fresh one which expanded the operating boundaries of

464 salinity gradient resource, and ii) dilution and concentration of feed and draw solution,

465 respectively, along the PRO module in a full POR module has not been accounted for the

466 limited area PRO system. 
468 For $5 \mathrm{M}-0.7 \mathrm{M}$ salinity gradient operating on the PRO mode, the values of $E_{\text {eff } 1}$ and $E_{\text {eff2 }}$ 469 were $0.47 \mathrm{kWh} / \mathrm{m}^{3}$ and $0.56 \mathrm{kWh} / \mathrm{m}^{3}$, respectively; the corresponding values for the FO 470 mode were $0.27 \mathrm{kWh} / \mathrm{m}^{3}$ and $0.61 \mathrm{kWh} / \mathrm{m}^{3}$, respectively [Figure $7 \mathrm{~B}$ ]. $E_{\text {effi }}$ was $43 \%$ and

$47124 \%$ of the $E_{m}$ for the PRO and FO modes respectively, whereas $E_{\text {eff } 2}$ was $50 \%$ and $55 \%$ of

472 the $E_{m}$ for the PRO and FO mode respectively. $E_{\text {efft }}$ was $1.03 \mathrm{kWh} / \mathrm{m}^{3}$ and $0.88 \mathrm{kWh} / \mathrm{m}^{3}$

473 for the PRO and FO mode respectively; these values are lower than the $E_{m}$ of $5 \mathrm{M}-0.68 \mathrm{M}$

474 salinity gradient, $1.11 \mathrm{kWh} / \mathrm{m}^{3}$ [Figure 7B]. $E_{\text {efft }}$ of the PRO mode was $26 \%$ higher than

475 that of the FO mode for $5 \mathrm{M}-0.6 \mathrm{M}$ salinity gradient whereas the difference was $15 \%$

476 between the PRO and FO mode for 5M-0.7M salinity gradient.

477

478 Simulation results show that $E_{m}$ was higher than the $E_{\text {eff }}$ of the first stage of the DSPRO

479 process. Adding a second PRO stage reduced the gap between $E_{m}$ and $E_{\text {eff }}$ but DSPRO

480 process performed better in the PRO mode than in the FO mode because of the higher

481 CP and RSD in the FO mode. PRO mode is more suitable for seawater and freshwater

482 feed solutions which can be treated by conventional processes whereas FO mode is

483 suitable for a low quality feed solutions. It should be noted that the total $E_{\text {eff }}$ is strongly

484 dependent on the intrinsic properties of the PRO membrane and higher performance

485 can be achieved by reducing the effects of CP and RSD.

486

487 


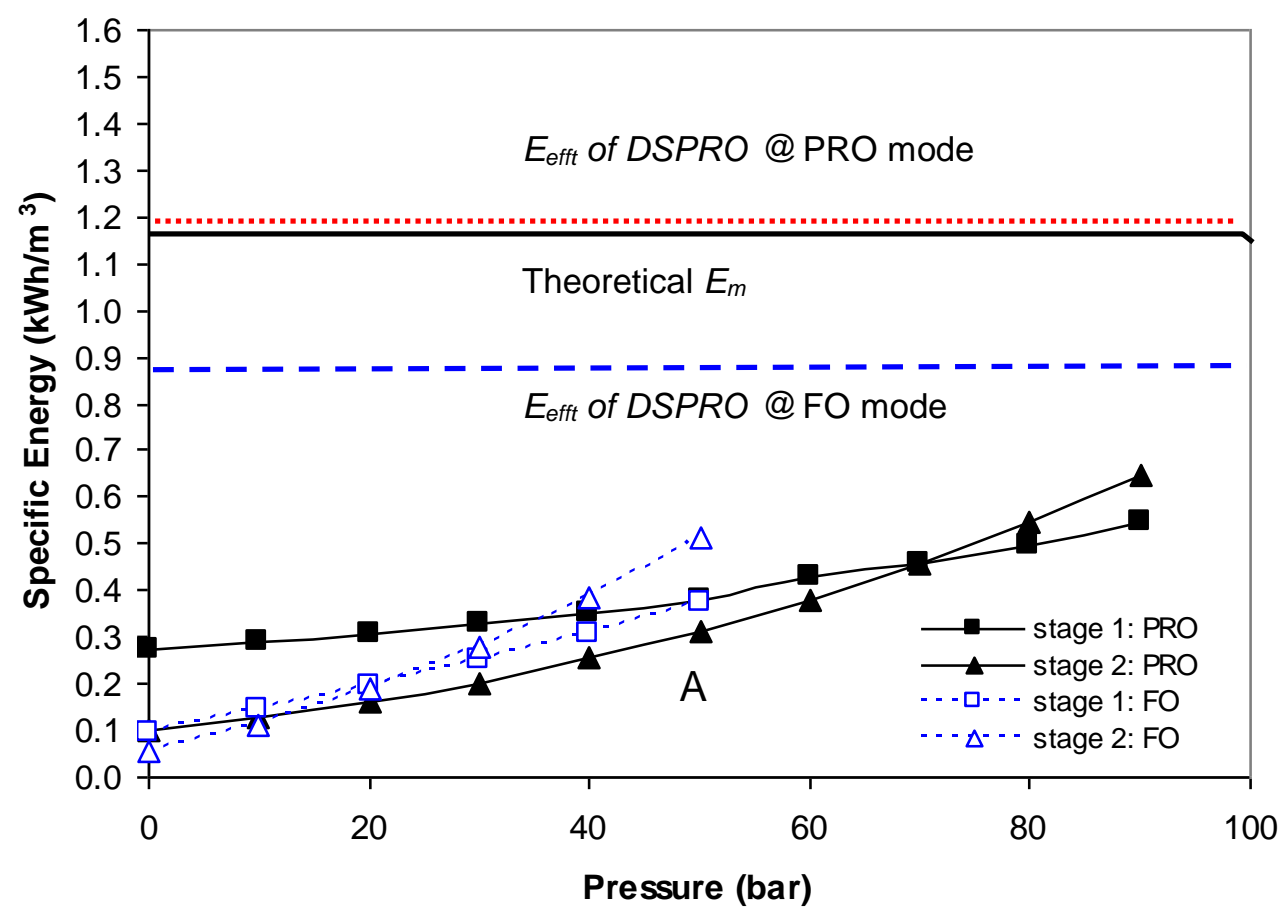

488

489

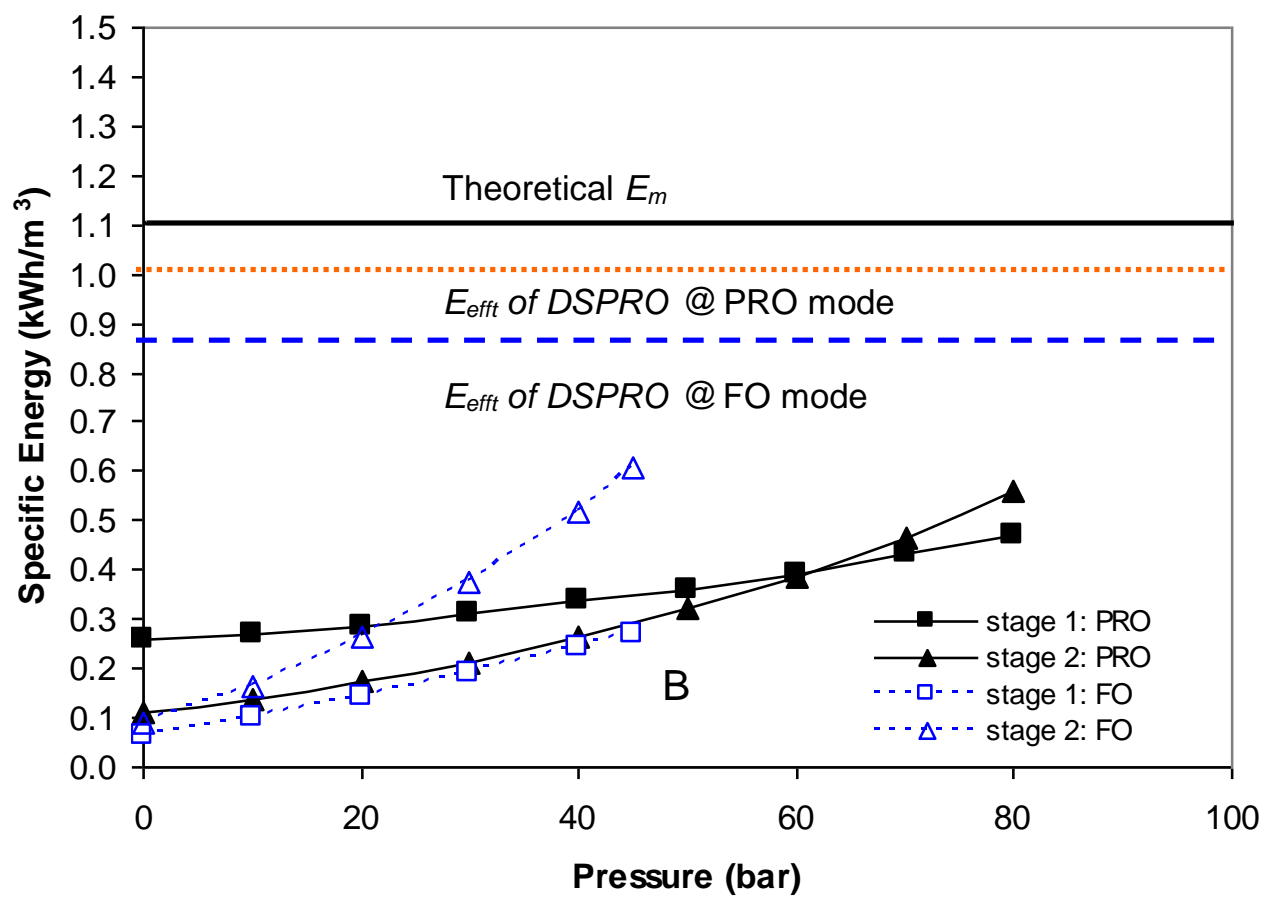


491 Figure 7: Impact of feed pressure on the maximum specific energy of DSPRO at different

492 salinity gradient resources A) $5 \mathrm{M}-0.6 \mathrm{M}$ B) $5 \mathrm{M}-0.68 \mathrm{M} \mathrm{g} / \mathrm{L}$. Theoretical maximum energy,

$493 E_{m}$ (solid line), theoretical effective $E_{m}$ of PRO mode (intermittent line), and theoretical

$494 \quad$ effective $E_{m}$ of FO mode (dashed line)

495

496 Conclusion:

497

498 The impact of membrane orientation on the performance of the DSPRO was evaluated

499 using different salinity gradients. Results showed that performance of the DSPRO was

500 higher at lower feed solution concentrations. High feed concentrations affected the

501 process performance significantly and particularly the second stage, which becomes

502 superfluous at high feed concentrations. Furthermore, the DSPRO process performed

503 better when was operating on the PRO mode with a maximum PWn-tot 5 times higher

504 than that on the FO mode. Severe concentration polarization and reverse salt diffusion

505 were responsible for the underperformance of the DSPRO operating on the FO mode.

506 the contribution of the second stage to the total power generation in the DSPRO process

507 was inconsiderable when it was operated on the FO mode, particularly at low draw

508 solution concentrations; i.e. $2 \mathrm{M}-0.6 \mathrm{M}$ and $2 \mathrm{M}-0.01 \mathrm{M}$ salinity gradients. For the PRO

509 mode, $32 \%$ increase in the power generation was achieved in the second stage for $2 \mathrm{M}$ -

$5100.01 \mathrm{M}$ salinity gradient resource. The results indicate that the performance of the

511 DSPRO varies according to the type of the salinity gradient resource and membrane

512 orientation, which should be considered in the design criteria of the DSPRO plant. 


\section{References:}

515

516 [1] A. Altaee, A. Sharif, G. Zaragoza, N. Hilal, Dual stage PRO process for power

517 generation from different feed resources, Desalination, 352 (2014) 118-127.

518 [2] A. Altaee, G. Zaragoza, E. Drioli, J. Zouh, Evaluation the Potential and Energy

519 Efficiency of Dual Stage Pressure Retarded Osmosis Process, Applied Energy, V 199

520 (2017), 359-369

521 [3] A. Altaee, P. Palenzuela, G. Zaragoza, A. Alhathal AlAnezi, Single and Dual Stage

522 Closed-Loop Pressure Retarded Osmosis for Power Generation: Feasibility and 523 Performance, Applied Energy, V 191, (2017), 328-345

524 [4] A. Altaee, A. Sharif, G. Zaragoza, Dual stage PRO process for power generation from 525 different feed resources, European Desalination Conference, 10-14 May 2015 Palermo, 526 Italy

527 [5] C. Y. Tang, Q. She, W. C.L. Lay, R. Wang, A. G. Fane, Coupled effects of internal 528 concentration polarization and fouling on flux behavior of forward osmosis membranes

529 during humic acid filtration, Journal of Membrane Science, V 354 (2010), 123-133.

530 [6] S. Loeb, One hundred and thirty benign and renewable megawatts from Great Salt

531 Lake? The possibilities of hydroelectric power by pressure-retarded osmosis,

532 Desalination, V 141 (2001), 85-91

533 [7] S. Loeb, Energy production at the Dead Sea by pressure-retarded osmosis: challenge

534 or chimera? Desalination, V 120 (1998), 247-262 
535 [8] D. D. Anastasio, J. T. Arena, E. A. Cole, J. R. McCutcheon, Impact of temperature on

536 power density in closed-loop pressure retarded osmosis for grid storage, Journal of

537 Membrane Science, V 479 (2015), 240-245

538 [9] S. E. Skilhagen, J.E. Dugstad, R.J. Aaberg, Osmotic power - power production based

539 on the osmotic pressure difference between waters with varying salt gradients,

540 Desalination, V 220 (2008) 476-482.

541 [10] Y. Gao, Y-N. Wang, W. Li, C. Y. Tang, Characterization of internal and external

542 concentration polarizations during forward osmosis processes, Desalination, $\vee 338$

543 (2014), 65-73

544 [11] S. Loeb, L. Titelman, E. Korngold, J. Freiman, Effect of porous support fabric on

545 osmosis through a Loeb-Sourirajan type asymmetric membrane, Journal of Membrane

546 Science, V 129 (1997). 243-249

547 [12] M. Kurihara, M. Hanakawa, Mega-ton Water System: Japanese national research

548 and development project on seawater desalination and wastewater reclamation,

549 Desalination, $V(308)$ 2013, 131-137

550 [13] K. Saito, M. Irie, S. Zaitsu, H. Sakai, H. Hayashi, A. Tanioka, Power generation with

551 salinity gradient by pressure retarded osmosis using concentrated brine from SWRO

552 system and treated sewage as pure water, Desalination and Water Treatment, $\vee 41$

553 (2012), 114-121.

554 [14] N-N. Bui 1, J. T. Arena, J.R. McCutcheon, Proper accounting of mass transfer 555 resistances in forward osmosis: Improving the accuracy of model predictions of

556 structural parameter, Journal of Membrane Science, V 492 (2015), 289-302 
557 [15] Great Salt Lake, Utah, Water-Resources Investigations Report 1999-4189 April 2007

558 https://pubs.usgs.gov/wri/wri994189/PDF/WRI99-4189.pdf . 25/05/2017

559 [16] K. Touati, F. Tadeo, Study of the Reverse Salt Diffusion in pressure retarded osmosis:

560 Influence on concentration polarization and effect of the operating conditions,

561 Desalination, V 389 (2016), 171-186

562 [17] J. Su, T-S. Chung, Sub layer structure and reflection coefficient and their effects on

563 concentration polarization and membrane performance in FO processes, Journal of

564 Membrane Science, V 376 (2011), 214-224

565 [18] E. Nagy, A general, resistance-in-series, salt-and water flux models for forward

566 osmosis and pressure-retarded osmosis for energy generation, Journal of Membrane 567 Science, V 460 (2014), 71-81.

568 [19] K.L. Lee, R.W. Baker, H.K. Lonsdale, Membranes for power generation by pressure569 retarded osmosis, Journal of Membrane Science, V 8 (1981), 141-171.

570 [20] A. Achilli, T. Y. Cath and A. E. Childress, Power generation with pressure retarded

571 osmosis: An experimental and theoretical investigation, Journal of Membrane Science, $\mathrm{V}$ $572343(2009), 42-52$.

573 [21] A. Altaee, G. J. Millar, G. Zaragoza, Integration and Optimization of Pressure

574 Retarded Osmosis with Reverse Osmosis for Power Generation and High Efficiency

575 Desalination, Energy, V 103 (2016), 110-118.

576 [22] W. He, Y. Wang, M. H. Shaheed, Enhanced energy generation and membrane 577 performance by two-stage pressure retarded osmosis (PRO), Desalination, V 359 (2015), $578 \quad 186-199$ 
579 [23] S. Lin, A. P. Straub, M. Elimelech, Thermodynamic limits of extractable energy by 580 pressure retarded osmosis, Energy Environmental Science, V 7 (2014), 2706-2714

581 [24] A. Altaee, A. Sharif, Pressure Retarded Osmosis: Advancement in the Process 582 Applications for Power Generation and Desalination, Desalination, V 356 (2015), 31-46.

583 [25] Q. She, Y. K. W. Wonga, S. Zhao, C. Y. Tang, Organic fouling in pressure retarded

584 osmosis: Experiments, mechanisms and implications, Journal of Membrane Science, $\mathrm{V}$ $585428(2013), 181-189$.

586

587

588 